\title{
Incidencia de los impuestos prediales en los ingresos municipales del Gobierno Autónomo Descentralizado Municipal del Cantón Sucúa, en los períodos 2014 y 2015
}

\section{Incidence of Land Tax in Municipal Income of the Municipal Decentralized Autonomous Government of Cantón Sucúa, in the periods 2014 and 2015}

\author{
López Jara, Ana Alexandra ${ }^{1 *}$ y Calle Alvarado, Marcelo Alejandro ${ }^{1}$ \\ ${ }^{1}$ Universidad Católica de Cuenca \\ *alopezj@ucacue.edu.ec
}

DOI: https://doi.org/10.26871/killkana_social.v2i1.89

\begin{abstract}
Resumen
Esta investigación de naturaleza descriptiva y de tipo explicativa, detalla el origen del impuesto predial con su hecho generador, la reincidencia de la recaudación y el destino de los recursos provenientes del impuesto. El objetivo es analizar la variación existente y el impacto producto de la reinversión de dichos recursos en beneficio de los contribuyentes del cantón Sucúa, entre los periodos 2014 y 2015. Para efectos de la investigación se analizaron en términos administrativos y financieros los resultados económicos y de gestión del Gobierno Autónomo Descentralizado del Cantón Sucúa, a través un trabajo de campo: empleando los estados financieros, las cedulas presupuestarias y el Plan Operativo Anual del periodo investigado. Entre los resultados se conoce que el destino de los recursos obtenidos de los impuestos prediales, se ubica en el mejoramiento de la calidad de vida de los habitantes al incentivar la cultura, la preservación del patrimonio cultural y el impulso del turismo, siendo este un beneficio de goce colectivo.
\end{abstract}

Palabras clave: Impuestos Prediales, Ingresos Corrientes, Gestión Financiera.

\begin{abstract}
This investigation is of a descriptive and explanatory nature, by virtue of detailing the origin of the property tax with its generating event, the recidivism of the collection and the destination of the resources coming from the tax; The objective is to analyze the existing variation and the impact of the reinvestment of these resources for the benefit of the taxpayers of the Sucúa canton in the periods 2014 and 2015. For the purposes of the research, the economic and management results were analyzed in administrative and financial terms. of the Autonomous Decentralized Government of Cantón Sucúa, through a fieldwork: using the financial statements, the budgetary cedulas and the Annual Operative Plan of the investigated period. Among the results it is known that the destination of the resources obtained from property taxes is located in the improvement of the quality of life of the inhabitants by encouraging culture, the preservation of cultural heritage and the promotion of tourism, this being a benefit of collective enjoyment.
\end{abstract}

Key words: Property Taxes, Financial Management.

\section{Introducción}

El Estado, en conjunto con sus administradores seccionales, precisa obtener recursos económicos para financiar el gasto público, el mismo que está integrado por gasto corriente o de consumo, gasto de capital y gasto de transferencia. Los entes públicos se financian de los recursos que perciben de los ciudadanos, quienes están obligados a entregar una parte de su patrimonio como su aporte al sustento de los gastos públicos. Entre los ingresos corrien- tes del sector público, se encuentran los provenientes por la recaudación de tributos, entre ellos el impuesto predial. En el Ecuador, el impuesto predial, grava una propiedad o posesión inmobiliaria, por lo que los propietarios de bienes inmuebles cancelan una cuota anual. Este impuesto representa un ingreso permanente que no tiene consecuencias de alteración de la toma de decisiones y se ha convertido en una fuente principal de los ingresos locales administrados por los municipios seccionales. Es así que el Gobierno Autónomo Descentralizado Cantonal tiene la facultad de 
aplicar impuestos como el catastral a los predios urbanos y rurales; y es en el Código Orgánico de Organización Territorial, Autonomía y Descentralización (COOTAD), en su artículo 139, que hace mención del ejercicio de la competencia de formar y administrar catastros inmobiliarios:

"La formación y administración de los catastros inmobiliarios urbanos y rurales corresponde a los gobiernos autónomos descentralizados municipales, los que con la finalidad de unificar la metodología de manejo y acceso a la información deberán seguir los lineamientos y parámetros metodológicos que establezca la ley. Es obligación de dichos gobiernos actualizar cada dos años los catastros y la valoración de la propiedad urbana y rural". (Asamblea Nacional, 2010)

Los impuestos prediales constituyen ingresos municipales, los cuales están constituidos por ingresos tanto tributarios como no tributarios. De acuerdo al Código Orgánico de Organización Territorial, Autonomía y Descentralización (COOTAD) los impuestos prediales constituyen ingresos municipales tributarios, estos impuestos financian el presupuesto institucional, mediante la inversión en actividades de gestión y proyectos de obra pública en beneficio de la colectividad. Antes de profundizar sobre el origen y destino de los recursos obtenidos por los ingresos prediales es menester fundamentar el marco legal ecuatoriano para su administración.

\subsection{El impuesto a los predios urbanos y rústicos dentro de los tributos del Ecuador}

Desde tiempos remotos los ciudadanos de un territorio han estado en la obligación de contribuir económicamente en el financiamiento de los servicios públicos; este importe se calculaba sobre diferentes bases, desde la propiedad de un bien hasta la ausencia de un derecho, siendo las civilizaciones pioneras en aspectos fiscales: Egipto, Grecia, Roma y Gran Bretaña.

Al abordar sobre las causas de los tributos autores como: (Santiere, Gómez, y Rossignolo, 2000); (Alarcón, 2009); (Pinto Bernal, 2013); (Sauma y Trejos, 2014) presentan importantes alcances en sus estudios. Se reconoce que las finanzas del Estado ya no solo podían ser concebidas como despensa para hacer frente a las necesidades del soberano, sino que también se constituían en mecanismos de redistribución de la renta y espacios desde los cuales se podía promover el desarrollo económico. Los tributos deberían gravarse a cada contribuyente de acuerdo a sus posibilidades económicas, que fuesen totalmente claros para los ciudadanos, que facilitaran su pago, y por último, que permitieran la llegada de la mayor proporción de fondos recaudados a las arcas del estado. En tal razón, (González Ortiz, 2010), define al tributo como la obligación legalmente impuesta al ciudadano, por la que se exige a éste la realización del pago de una suma de dinero a un ente público como contribución al sostenimiento de los gastos públicos.
Por otra parte, (Santiere y cols., 2000), aclara que un sistema tributario satisface al valor "equidad" cuando los sectores de mayor capacidad contributiva (los de mayor ingreso) pagan una cuota de impuesto más elevada relativamente a los demás sectores. Los gastos públicos sociales en general cumplen con el criterio beneficiando más a los sectores desprotegidos o de menores recursos, ahí surge la reflexión ¿no podría dejarse la función progresiva a los gastos sin pedir igual condición a los impuestos? La experiencia de economías más maduras indica que el hecho de que los gastos sean progresivos no excluye que la asignación de los tributos también lo sea.

Un tributo en el criterio de González Ortiz (2010) corresponde a una obligación de pago por parte de los ciudadanos como respuesta a la acción coercitiva del estado, los mismos que tiene el carácter de obligatorio, dinerario y contributivo. El código tributario reitera que los tributos son herramientas que procuran recaudar fondos para el servicio público, con fines productivos y de desarrollo social; siendo de las municipalidades y consejos provinciales la recaudación eficiente, resolución de reclamaciones y absolución de las consultas tributarias. Como se mencionó, los tributos tienen como objetivo primordial cubrir el gasto público generando bienestar en la comunidad. Los tributos se clasifican en: impuestos, tasas y contribuciones.

Impuestos: El libro "Historia de los Impuestos en el Ecuador" de los autores Juan J. y Cepeda Miño, aborda el estudio de los impuestos y señala que: "son tributos que cobra el Estado (sujeto activo) a los "contribuyentes" (sujeto pasivo), de manera común, general y obligatoria y que estos deben pagarlos en virtud de poseer un patrimonio, realizar actividades para recibir rentas o ingresos o transferir y circular bienes y servicios personales. (Paz y Miño Cepeda, 2015)

Tasas: consiste en el valor que se cobra por un servicio ofrecido, en este caso no necesariamente existe una contraprestación, por ejemplo, tasa por la recolección de basura por el camión basurero municipal. Para Juan J. y Cepeda Miño, las tasas: "Son tributos que pagan los contribuyentes que se benefician, en forma específica, de ciertos servicios públicos y que, por tanto, solo son obligatorios para quienes reciben esas prestaciones desde el Estado. (Paz y Miño Cepeda, 2015)

Contribuciones: son los valores que pagan particulares, por el beneficio recibido por la elaboración de una obra pública, por ejemplo, cuando realizan las veredas en los domicilios y cobran por esa contribución de mejoras (Ruoti, 2006). Los autores Juan J. y Cepeda Miño, definen a las contribuciones como; “... tributos que solo tienen que pagar ciertos sujetos pasivos que se benefician por obras realizadas por el Estado y que favorecen el patrimonio de esos mismos contribuyentes". (Paz y Miño Cepeda, 2015)

Dentro de este escenario sobre el comportamiento del tributo, conocemos que en el Ecuador la administración de los tributos se fundamenta en el Código tributario (2005); 
la Constitución de la República (2008); la Ley Orgánica del Régimen Tributario Interno (2010); El Reglamento de Aplicación a la Ley Orgánica del Régimen Tributario Interno (2010); el Código Orgánico de Organización Territorial, Autonomía y Descentralización (COOTAD) 2010, siendo documentos rectores para la determinación, recaudación y administración de los recursos públicos.

De acuerdo al Código Orgánico de Organización Territorial Autonomía y Descentralización las municipalidades en cumplimiento con sus competencias administran los recursos del Estado sean estos provenientes de impuestos, tasas y contribuciones de mejoras; en el ecuador, los impuestos más comunes de carga obligatoria por los ciudadanos se gravan sobre:

- La Propiedad: los predios urbanos, a los predios rurales, a la inscripción en el registro de la propiedad o en el registro mercantil, las transmisiones de dominio, de vehículos motorizados de transporte terrestre, de alcabalas, a los activos totales, de vehículos motorizados de transporte aéreo y acuático, a la propiedad de inmuebles urbanos para vivienda de interés social, impuesto a los activos en el exterior, sobre el patrimonio, sobre bienes inmuebles y derechos representativos de capital,

- El Consumo de Bienes y Servicios: al consumo de cigarrillos, al consumo de cerveza, al consumo de bebidas gaseosas, al consumo de alcohol y productos alcohólicos, al consumo de bienes suntuarios, a las telecomunicaciones, a los espectáculos públicos,

- El Valor Agregado: débitos del período, al valor agregado, recaudado por el SRI, al valor agregado, recaudado por el SENAE

- El Comercio Internacional: arancelarios a la importación, tarifa de salvaguardia, $0.7 \%$ de exportaciones de banano.

- La Actividad Hidrocarburífera: a la renta de empresas petroleras, a la renta de empresas petroleras de prestación de servicios, a la renta por ventas internas de derivados del petróleo, a la facturación de las empresas nacionales y extranjeras de prestación de servicios a petroecuador, gravamen a la tarifa de oleoducto.

- Impuestos Diversos: a las tarjetas de crédito, a las operaciones de crédito, patentes comerciales, industriales, financieras, inmobiliarias, profesionales y de servicios, a la salida del país, sobre contratos de construcción o estudios celebrados con el sector público, sobre reajuste de precios en la contratación pública, $1 \%$ a la compra de vehículos usados, régimen impositivo simplificado, impuesto ambiental por contaminación vehicular

De los impuestos antes citados, en esta investigación se analiza el impuesto predial, gravado a los propietarios de un bien inmueble; por este derecho, los propietarios cancelan una cuota anual a la administración tributaria de los municipios seccionales. Las Municipalidades, en orden a lo que señala el art. 139 del COOTAD, tienen la facultad de aplicar el impuesto catastral a los predios urbanos y rurales; "La formación y administración de los catastros inmobiliarios urbanos y rurales corresponde a los gobiernos autónomos descentralizados municipales, los que con la finalidad de unificar la metodología de manejo y acceso a la información deberán seguir los lineamientos y parámetros metodológicos que establezca la ley". (Asamblea Nacional, 2010).

El Impuesto urbano y rural se constituirá a las circunscripciones integradas de los cantones respectivamente como establezcan los organismos reguladores de impuestos y a través de ordenanzas públicas el Gobierno Autónomo Descentralizado Cantonal, como compromiso fundamental, efectuar el cumplimiento del deber de recaudar el impuesto predial, proveniente de una propiedad o posesión inmobiliaria, por los propietarios de manera anual.

El Impuesto predial Urbano, es un impuesto que cobran los municipios sobre bienes raíces urbanos, es decir sobre el valor de los terrenos, edificaciones e instalaciones que constituyan parte de la zona urbana. Este impuesto se debe cancelar cada año, inicia desde el 1 de enero y tiene fecha de vencimiento al 31 de diciembre, con descuentos graduales según la fecha de pago. Se calcula sobre la base del avaluó del lote y la construcción; en zonas urbanas se calcula aplicando un porcentaje que oscila entre 0.25 por mil y 5 por mil, como lo establece el COOTAD en el art, 504. El porcentaje aplicado se fija en base a la Ordenanza del Consejo Municipal.

Impuesto predial Rural, es un impuesto que se le carga a los propietarios o poseedores de bienes raíces situados fuera de los límites de las zonas urbanas, los obligados al pago del impuesto por concepto de predio rural deberán realizarlo ante la Municipalidad donde se encuentre ubicado el bien. Los elementos que integran la propiedad rural son: tierras, edificios, maquinaria agrícola, ganado y otros semovientes, plantaciones agrícolas y forestales. La tarifa por concepto de impuesto predial rural será determinada a través de la ordenanza municipal o metropolitana, la cual no podrá ser inferior a 0.25 por mil, ni superior a 3 por mil, como lo establece el Art. 517 del COOTAD.

El pago del impuesto se lo realizará en dos dividendos: hasta marzo 1 el primer dividendo y hasta septiembre 1 el segundo dividendo; los pagos efectuados hasta 15 días antes de las fechas estipuladas, tendrán un descuento del $10 \%$ anual. El art. 495 del COOTAD se reconoce que el valor que se establece a la propiedad, se realizará mediante la suma del valor del suelo y, de haberlas, el de las construcciones que se hayan edificado sobre el mismo. Este valor constituye el valor intrínseco, propio o natural del inmueble y servirá de base para la determinación de impuestos y para otros efectos tributarios, y no tributarios". (Asamblea Nacional, 2010)

Independientemente del valor intrínseco de la propiedad, y con fines tributarios, los municipios podrán establecer criterios de medida del valor de los bienes inmuebles en factores de aumento del valor del bien inmueble que no se pueda atribuir a su titular. Para efectos del cálculo 
de impuesto predial urbano, se observará el art. 504 del COOTAD, que señala: "Banda impositiva.- al valor de la propiedad urbana se aplicara un porcentaje que oscilará entre un mínimo de cero punto veinticinco por mil $(0.25 \%)$ y un máximo del cinco por mil $(5 \%)$ que será fijado mediante ordenanza por cada consejo municipal". (Asamblea Nacional, 2010).

\section{Metodología}

Esta investigación es de tipo explicativa - descriptiva y de naturaleza de campo, elaborada bajo un enfoque mixto cuantitativo - cualitativo; se fundamentó en la revisión de los estados financieros, las cédulas presupuestarias de ingresos y gastos, y el presupuesto institucional de los años 2014 y 2015. En base a un análisis financiero, se determinó resultados económicos con la aplicación de indicadores de: solvencia financiera, dependencia financiera, autonomía financiera, recaudación tributaria y recaudación de ingresos del presupuesto. Lo que permitió evaluar el rendimiento financiero que provocan los ingresos tributarios originados por la recaudación de los impuestos prediales (urbanos y rurales) sobre los gastos corrientes, de inversión y de capital del Gobierno Autónomo Descentralizado del Cantón Sucúa.

\section{Resultados y Discusión}

El Gobierno Autónomo Descentralizado del cantón Sucúa se crea en fundamento a la necesidad de alcanzar el desarrollo integral de su comunidad, privilegiando al ser humano como centro para un desarrollo sustentable y equilibrado con el entorno para lograr el Buen Vivir, de acuerdo al Registro Oficial $N^{\circ} 457$ del 14 de enero de 2016. El objetivo de la municipalidad, de acuerdo a la planificación estratégica se describe de la siguiente manera:

"Mejorar la calidad de vida de la población del cantón Sucúa mediante la prestación de servicios públicos, con la implementación de la participación ciudadana para alcanzar el progreso equitativo, solidario, sustentable, social y económico con una adecuada planificación y administración de la gestión pública, con carácter intercultural y plurinacional hacia una ciudad de paz con alianzas para el desarrollo en un ambiente sano y equilibrado, para conseguir el Sumak Kawsay". (Dirección de Planificación Estratégica, 2017)

Como se ha mencionado anteriormente dentro de los impuestos bajo la administración del Gobierno Cantonal, se encuentran el impuesto sobre la propiedad urbana y rural; siendo de interés para esta investigación el comportamiento de los ingresos tributarios por concepto de predios urbanos y rurales del Gobierno Autónomo Descentralizado del Cantón Sucúa.
Tabla 1 Predios Urbanos cantón Sucúa

\begin{tabular}{|l|l|l|l|l|}
\hline \multicolumn{3}{|c|}{ Predios urbanos } & \multicolumn{1}{c|}{ Valor a recaudar } \\
\hline \multicolumn{1}{|c|}{ Predios } & $\mathbf{2 0 1 4}$ & $\mathbf{2 0 1 5}$ & $\mathbf{2 0 1 4}$ & $\mathbf{2 0 1 5}$ \\
\hline Sucúa & 5216 & 5101 & $\$ 173.437,98$ & $\$ 170.185,76$ \\
\hline Huambi & 663 & 668 & $\$ 9.907,21$ & $\$ 10.147,50$ \\
\hline Santa Marianita & 288 & 292 & $\$ 3.894,55$ & $\$ 3.980,51$ \\
\hline Total & 6167 & 6061 & $\$ 187.239,74$ & $\$ 184.313,77$ \\
\hline
\end{tabular}

Fuente: Gobierno Autónomo Descentralizado del Cantón Sucua

Como punto de partida en este estudio, se conoce que el número de predios urbanos registrados en el año 2014 fueron de 6167, mientras que en el 2015 disminuyeron hasta 6061(Tabla Nro. 1); estos originaron un valor a recaudar en el año 2014 de 187,239, 74, yenel2015de184.313,77 por concepto de predios urbanos del Cantón Sucúa (Gráfico Nro. 1).

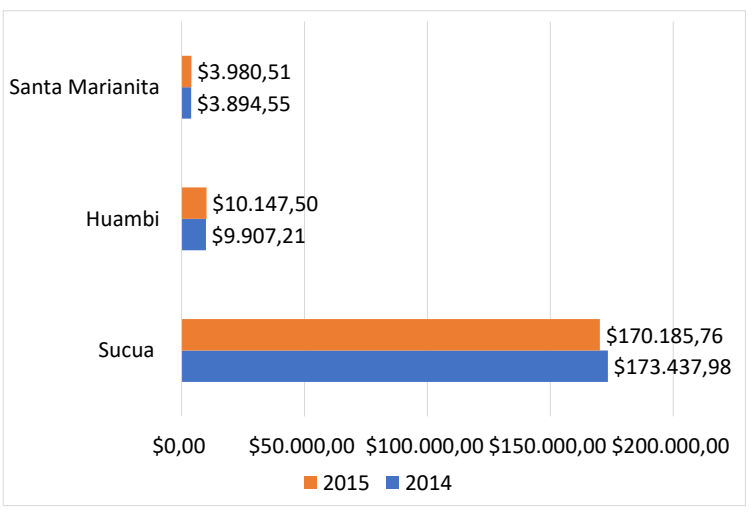

Figura 1. Valores a recaudar Predios Urbanos Cantón Sucúa Fuente: Gobierno Autónomo Descentralizado del Cantón Sucúa

El comportamiento de los valores a recaudar por concepto de predios urbanos en la parroquia Sucúa se muestra con montos más significativos en el año 2014 con un valor de \$173.437,98 mientras que para el año 2015 descendió a $\$ 170.186,76$ esto se debe a las actualizaciones catastrales que se realiza anualmente.

Tabla 2 Predios Rurales cantón Sucúa

\begin{tabular}{|l|l|l|l|l|}
\hline \multicolumn{3}{|c|}{ Predios rurales } & \multicolumn{1}{c|}{ Valor a recaudar } \\
\hline \multicolumn{1}{|c|}{ Predios } & $\mathbf{2 0 1 4}$ & $\mathbf{2 0 1 5}$ & $\mathbf{2 0 1 4}$ & $\mathbf{2 0 1 5}$ \\
\hline Sucúa & 2521 & 2514 & $\$ 17.113,40$ & $\$ 17.486,64$ \\
\hline Asunción & 74 & 80 & $\$ 470,39$ & $\$ 510,07$ \\
\hline Huambi & 756 & 788 & $\$ 5.408,03$ & $\$ 5.826,28$ \\
\hline Santa Marianita & 652 & 652 & $\$ 5.071,49$ & $\$ 4.924,23$ \\
\hline
\end{tabular}

Fuente: Gobierno Autónomo Descentralizado del Cantón Sucúa

Por otra parte, la cantidad de predios rústicos en el año 2015 ha incrementado en un $1 \%$ en comparación con el 2014; siendo 4003 predios rústicos registrados en el año base. (Tabla Nro. 2) 


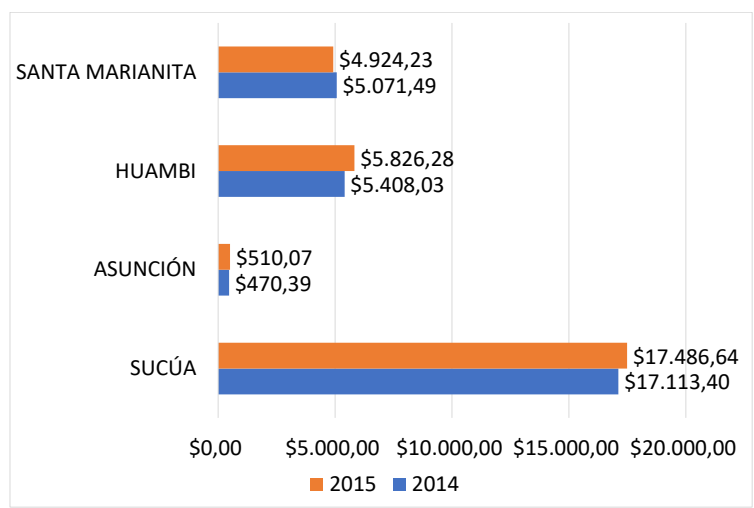

Figura 2. Valores a recaudar Predios Rurales Cantón Sucúa

Fuente: Gobierno Autónomo Descentralizado del Cantón Sucúa

En la representación gráfica Nro. 2 se demuestra que el mayor valor de catastro predial rústico para el 2014 corresponde a la parroquia Sucúa, con un total de $\$ 17.113,40$; este resultado debido a que es el cantón de mayor extensión territorial. Poor otro lado la parroquia que está representada con el monto menor por concepto de catastro predial es Asunción, con un valor de $\$ 470,29$; esto debido a que esta parroquia solo cuenta con predios rústicos, no califica aún con lotes urbanos. (Gráfico Nro. 2).

De acuerdo a la planificación presupuestaria el valor recaudado por concepto de impuestos prediales urbano y rústico en el año 2014 fue de \$133.475,97 y en el 2015 de \$131.134,14; sin embargo, lo que se logró recaudar en esos periodos fue de $\$ 113.758,44$ y $\$ 114.046,64$ respectivamente, tal como se muestra la Tabla Nro. 3.

Tabla 3 Catastro Predial Urbano y Rústico, declarados frente a lo recaudado periodos 2014 y 2015

\begin{tabular}{|c|c|c|c|}
\hline Año & Catastro & $\begin{array}{c}\text { Emitido } \\
\text { (Descuentos) }\end{array}$ & Recaudado \\
\hline 2014 & $\$ 215.303,05$ & $\$ 133.475,97$ & $\$ 113.758,44$ \\
\hline 2015 & $\$ 213.060,99$ & $\$ 131.134,14$ & $\$ 114.046,64$ \\
\hline
\end{tabular}

Fuente: Gobierno Municipal del Cantón Sucúa-Dirección Administrativa

En observancia a los resultados de la recaudación del catastro predial urbano y rústico se evaluó el nivel de efectividad de estos recursos; para efectos, se aplicaron indicadores financieros presupuestarios, los mismos que se detallan a continuación (Tabla Nro 4):

De acuerdo al análisis financiero antes presentado la mayor parte de los ingresos del Presupuesto Institucional son provenientes de Transferencias del Gobierno Central en un $86,44 \%$ en el año 2014 y 88,26\% en el 2015. Otro elemento de interés corresponde al ratio de presión fiscal por habitante; el mismo que ha disminuido del 19,77\% al $16,17 \%$ con relación a impuestos y tasas fiscales como se observa a continuación:
Tabla 5 Impuestos y Tasas Fiscales

\begin{tabular}{|l|l|l|}
\hline \multicolumn{1}{|c|}{ Impuestos, Tasas Fiscales } & \multicolumn{1}{c|}{$\mathbf{2 0 1 4}$} & \multicolumn{1}{c|}{$\mathbf{2 0 1 5}$} \\
\hline $\begin{array}{l}\text { A la utilidad por la venta de predios } \\
\text { urbanos }\end{array}$ & $\$ 124.155,30$ & $\$ 70.140,68$ \\
\hline A los predios urbanos & $\$ 127.081,69$ & $\$ 125.076,75$ \\
\hline A los predios rusticos & $\$ 6.394,28$ & $\$ 6.057,39$ \\
\hline A las transmisiones de dominio & $\$ 8.435,45$ & $\$ 1.823,53$ \\
\hline Alcabalas & $\$ 59.851,21$ & $\$ 52.395,98$ \\
\hline Activos totales & $\$ 5.946,25$ & $\$ 7.036,25$ \\
\hline $\begin{array}{l}\text { Patentes comerciales, industriales y de } \\
\text { servicios }\end{array}$ & $\$ 12.044,80$ & $\$ 60.420,13$ \\
\hline Al desposte de ganado & $\$ 8.432,00$ & $\$ 8.478,40$ \\
\hline Acceso a lugares publicos & $\$ 657,40$ & $\$ 776,80$ \\
\hline Ocupacion de lugares publicos & $\$ 13.872,07$ & $\$ 12.135,26$ \\
\hline Especies fiscales & $\$ 14.059,60$ & $\$ 13.760,80$ \\
\hline
\end{tabular}

Fuente: Gobierno Municipal del Cantón Sucúa-Dirección Administrativa

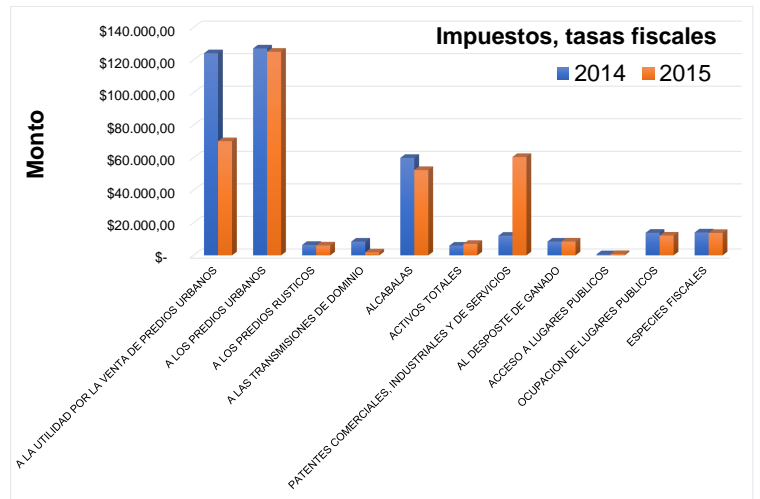

Figura 3. Relación de Impuestos, Tasas Fiscales 2014 y 2015

Fuente: Gobierno Autónomo Descentralizado del Cantón Sucúa

La ratio de presión fiscal demuestra que las variaciones afectan al nivel social e incrementan las contribuciones de la ciudadanía haciendo que esta no pueda adquirir una vivienda propia y se empeñe en abrir un negocio pagando un alquiler. Por otro lado, de acuerdo a la clasificación presupuestaria los ingresos prediales coadyuvan en el fortalecimiento de los ingresos corrientes, en efecto a continuación se presenta el valor proporcional de estos resultados en los periodos 2014 y 2015 (Tabla Nro. 6):

Tabla 6 Equivalente de Ingresos Prediales sobre los Ingresos Corrientes

\begin{tabular}{cccc}
\hline AÑO & $\begin{array}{c}\text { Ingresos } \\
\text { Corrientes }\end{array}$ & $\begin{array}{c}\text { Ingresos } \\
\text { Prediales }\end{array}$ & Porcentaje \\
\hline 2014 & $\$ 1.193 .750,00$ & $\$ 133.475,97$ & $11,18 \%$ \\
2015 & $\$ 1.453 .438,54$ & $\$ 131.134,14$ & $9,02 \%$ \\
\hline
\end{tabular}

Fuente: Gobierno Municipal del Cantón Sucúa-Dirección Administrativa

El registro catastral influye sobre el valor a recaudar por concepto de ingresos prediales; en relación al número de predios, en el año 2014 existió un mayor número de predios en relación al 2015; este resultado se reflejó en el presupuesto catastral, siendo en el año 2014 de \$ 133.475,97, mientras que en 2015 de $\$ 131.134,14$. Este resultado derivó para que en el año 2014, los ingresos por recaudación de Impuestos Prediales correspondan al $11,18 \%$ de los Ingresos Corrientes, mientras que en el año 
Tabla 4 Indicadores Financieros Presupuestarios

\begin{tabular}{|c|c|c|c|c|c|}
\hline \multirow{3}{*}{ Solvencia Financiera } & Fórmula & 2014 & $\%$ & 2015 & $\%$ \\
\hline & Ingresos Corrientes & 1193750,00 & \multirow{2}{*}{$66,57 \%$} & 1453438,54 & \multirow{2}{*}{$71,30 \%$} \\
\hline & Gatos Corrientes & 1793133,01 & & 2038581,72 & \\
\hline \multicolumn{6}{|c|}{$\begin{array}{l}\text { El Gobierno Autónomo Descentralizado Municipal del Cantón Sucúa, demuestra que en el año 2015, los ingresos corrientes son superiores, con } \\
\text { comparación con el 2014, esto se debe a que las partidas presupuestarias: a) impuestos y b) transferencias y donaciones corrientes se han incre- } \\
\text { mentado considerablemente. En el mismo año } 2015 \text { los gastos corrientes se incrementaron especialmente en las partida presupuestarias de: } \\
\text { a) gastos de bienes y consumo y b) espectáculos culturales y sociales, preservación del patrimonio cultural, en resultados de la realización de las } \\
\text { fiestas Cantonales de Sucúa. Es el incremento de sus ingresos corrientes que le permiten un mayor nivel de solvencia con respecto al año } 2014 \text {, } \\
\text { esto es, la capacidad para cubrir gastos corrientes con los ingresos corrientes en un } 66,57 \% \text { para el año } 2014 \text { y } 71,30 \% \text { en el año } 2015 \text {. }\end{array}$} \\
\hline \multirow{2}{*}{ Dependencia Financiera } & Ingresos de Transferencia & 6381750,48 & \multirow{2}{*}{$86,44 \%$} & 7170334,53 & \multirow{2}{*}{$88,26 \%$} \\
\hline & Ingresos Totales & 7383169,01 & & 8124559,83 & \\
\hline \multicolumn{6}{|c|}{$\begin{array}{l}\text { Se puede apreciar que el Gobierno Autónomo Descentralizado Cantonal, mantiene un alto nivel de dependencia financiera, esto es, del } 100 \% \text { de } \\
\text { ingresos, el 86,44\% para el año } 2014 \text { y el 88,26\% para el año } 2015 \text { han sido provenientes de transferencias del sector público; cabe resaltar la } \\
\text { gestión realizada por parte de la municipalidad para ser acreedores del financiamiento del Gobierno Central, con lo que se hace posible la ejecu- } \\
\text { ción de obras y mejoras en beneficio colectivo de la comunidad. }\end{array}$} \\
\hline \multirow{2}{*}{ Autonomía Financiera } & Ingresos Propios & 362171,08 & \multirow{2}{*}{$4,91 \%$} & 296236,59 & \multirow{2}{*}{$3,65 \%$} \\
\hline & Ingresos Totales & 7383169,01 & & 8124559,83 & \\
\hline \multicolumn{6}{|c|}{$\begin{array}{l}\text { En base a la autonomía financiera de la institución, se puede apreciar que en el año } 2015 \text { existe una disminución de los ingresos propios, esto es } \\
\text { en impuestos y tributos en relación al año } 2014 \text {, por lo que se demuestra que el porcentaje de participación de los ingresos por fondos propios so- } \\
\text { bre los ingresos totales es del } 4,90 \% \text { y } 3,65 \% \text {, para los años } 2014 \text { y } 2015 \text { respectivamente, la entidad mantiene un nivel bajo en lo que respecta } \\
\text { a generar por sus medios recursos propios. }\end{array}$} \\
\hline \multirow{9}{*}{ Recaudación Tributaria } & Recaudación Predial & 133475,97 & \multirow{2}{*}{$1,81 \%$} & 131134,14 & \multirow{2}{*}{$1,61 \%$} \\
\hline & Ingresos Totales & 7383169,01 & & 8124559,83 & \\
\hline & \multicolumn{5}{|c|}{$\begin{array}{l}\text { El Gobierno Autónomo Descentralizado del Cantón Sucúa, en los periodos } 2014 \text { y } 2015 \text {, presentan una dis- } \\
\text { minución en el monto de la recaudación predial, el mismo que se ve reflejado en el porcentaje equivalente } \\
\text { de los ingresos prediales sobre los ingresos totales; es así que del } 100 \% \text { de ingresos totales de la entidad, el } \\
1,81 \% \text { y el } 1,61 \% \text { equivale a ingresos por impuestos prediales para los años } 2014 \text { y } 2015 \text { respectivamente, } \\
\text { esto se debe a que en el año } 2015 \text { existió un número inferior de predios con relación al año 2014, debido a } \\
\text { la actualización de visa proyectadas. }\end{array}$} \\
\hline & Recaudación Tributos & 228695,11 & \multirow{2}{*}{$3,10 \%$} & 165102,45 & \multirow{2}{*}{$2,03 \%$} \\
\hline & Ingresos Totales & 7383169,01 & & 8124559,83 & \\
\hline & \multicolumn{5}{|c|}{$\begin{array}{l}\text { Existe una variante en la recaudación de tributos entre el año } 2014 \text { y } 2015 \text {, la recaudación de tributos es me- } \\
\text { nor para el año } 2015 \text {, siendo así que del } 100 \% \text { de ingresos totales el 3,10\% y el 2,03 \% respectivamente, } \\
\text { equivale a la recaudación en impuesto, tasas y contribuciones; los mismos que se orientan a los ingresos pro- } \\
\text { pios de la entidad como Gobierno Autónomo Descentralizado Cantonal. }\end{array}$} \\
\hline & Ingresos por Predios & 133475,97 & \multirow{2}{*}{$7,44 \%$} & 131134,14 & \multirow{2}{*}{$6,43 \%$} \\
\hline & Gastos Corrientes & 1793133,01 & & 2038581,72 & \\
\hline & \multicolumn{5}{|c|}{$\begin{array}{l}\text { Los ingresos prediales son similares en los años } 2014 \text { y } 2015 \text {, pero existe una diferencia representativa en los } \\
\text { gastos corrientes, en el año } 2015 \text { se incurrieron en mayores gastos especialmente en la partida presupuestaria } \\
\text { de gastos en bienes de uso y consumo; dentro de esta partida presupuestaria existe un incremento de los gas- } \\
\text { tos en la realización de las fiestas de cantonización. Por lo que, se obtuvo como resultado un indicador del } \\
7,44 \% \text { en el año } 2014 \text { y } 6,43 \% \text { en el año } 2015 \text { respectivamente, de ingresos prediales empleados para solven- } \\
\text { tar parte de los gastos corrientes de la institución. }\end{array}$} \\
\hline \multirow{2}{*}{ Presión Fiscal } & Impuestos, Tasas Fiscales & 362171,08 & \multirow{2}{*}{$19,77 \%$} & 296236,59 & \multirow{2}{*}{$16,17 \%$} \\
\hline & Número de Habitantes & 18318 & & 18318 & \\
\hline
\end{tabular}

2015, representen el 9,02\% del mismo objeto de estudio; demostrando una variación de porcentaje mayor en el año 2014. En relación al financiamiento que los ingresos prediales logran con los gastos corrientes, se conoce que alcanza en el año 2014 un $7.44 \%$, mientras que en el 2015 un $6.43 \%$ del total de gastos, es decir resultan insuficientes como para considerar una fuente de financiamiento sostenible. (Tabla Nro. 7)

Tabla 7 Equivalente de Ingresos Prediales sobre los Gastos Corrientes

\begin{tabular}{cccc}
\hline AÑO & $\begin{array}{c}\text { Gastos } \\
\text { Corrientes }\end{array}$ & $\begin{array}{c}\text { Ingresos } \\
\text { Prediales }\end{array}$ & Porcentaje \\
\hline 2014 & $\$ 1.793 .133,01$ & $\$ 133.475,97$ & $7,44 \%$ \\
2015 & $\$ 2.038 .581,72$ & $\$ 131.134,14$ & $6.43 \%$ \\
\hline
\end{tabular}

Fuente: Gobierno Municipal del Cantón Sucúa-Dirección Administrativa
El destino de los ingresos prediales se orientan hacia parte los gastos corrientes, por lo que se presentan las partidas presupuestarias de gasto corriente que han sido cubiertas con los ingresos prediales presupuestados para los años 2014 y 2015 respectivamente (Tabla Nro. 8):

Las partidas presupuestarias de gastos corrientes que se cubrieron con los ingresos prediales para el año 2014 fueron: a) la partida presupuestaria 530205 correspondiente a espectáculos culturales y sociales y preservación del patrimonio cultural en un total del $100 \%$, b) la partida presupuestaria 530306 alimentación con un financiamiento del $100 \%$ y c) la partida presupuestaria 510106 correspondiente a salarios unificados en donde se cubrió únicamente el $15.77 \%$ del total de gastos. En el año 2015, el comportamiento del destino de los recursos obtenidos de 
Tabla 8 Detalle de Gastos Corrientes cubiertos por los Ingresos Prediales de los años 2014 y 2015

\begin{tabular}{|l|l|l|l|l|l|}
\hline Cod. & Partida Presupuestaria & $\begin{array}{c}\text { Acumulado } \\
\text { Gastos 2014 }\end{array}$ & $\begin{array}{c}\text { Liquidado } \\
\text { (ing. Predial 2014) }\end{array}$ & $\begin{array}{c}\text { Acumulado } \\
\text { Gastos 2015 }\end{array}$ & $\begin{array}{c}\text { Liquidado } \\
\text { (ingr. Predial 2015) }\end{array}$ \\
\hline 5101 & Remuneraciones Basicas & & & & \\
\hline 510106 & Salarios Unificados & $\$ 53.164,69$ & $\$ 8.383,67$ & & \\
\hline 5103 & Remuneraciones Compensatorias & & & & \\
\hline 510306 & Alimentación & $\$ 2.266,00$ & $\$ 2.266,00$ & & \\
\hline 5302 & Servicios Generales & & & & \\
\hline 530205 & $\begin{array}{l}\text { Espectáculos Culturales Y Sociales, Pre- } \\
\text { servación Del Patrimonio Cultural }\end{array}$ & $\$ 122.826,30$ & $\$ 122.826,30$ & $\$ 183.429,81$ & $\$ 131.134,14$ \\
\hline \multicolumn{1}{|c|}{ Total Liquidado } & & $\$ 133.475,97$ & & $\$ 131.134,14$ \\
\hline
\end{tabular}

Fuente: Gobierno Municipal del Cantón Sucúa-Dirección Administrativa

la partida presupuestaria de gastos corrientes que se cubrió fue únicamente la partida 530205 espectáculos culturales y sociales y preservación del patrimonio cultural (Cubierta el $71,49 \%$ ). Esto se debe a que el monto para la realización de las festividades del Cantón Sucúa ascendió a un monto de $\$ 183.429,81$ para este año, monto superior al año anterior.

\section{Conclusiones}

El estado ecuatoriano de acuerdo a los documentos rectores en materia fiscal otorga la administración de los tributos a entidades creadas por ley para estas competencias y a los diversos niveles de Gobiernos Autónomos Descentralizados y Regímenes Especiales con el fin de garantizar su autonomía política, financiera y administrativa. Entre los principales tributos se encuentran los impuestos: a la propiedad, al consumo de bienes y servicios, al valor agregado, al comercio internacional, a la actividad hidrocarburífera e impuestos diversos.

Los ingresos propios del Gobierno Autónomo Descentralizado del Cantón Sucúa en el año 2014 fueron de \$ $362.171,08$ mientras que para el año 2015 esa cifra fue inferior, llegando a $\$ 296.236,59$, situación que orientó a que en el año 2015 la municipalidad tenga mayor dependencia de las transferencias del gobierno central. Por otro lado, los ingresos recaudados por concepto de impuestos prediales fueron de \$113.758,44 para el año 2014 y \$114.046,64 para el año 2015, lo que permitió en el año 2014 financiar solo el $7.44 \%$ de los gastos corrientes, mientras que en el año 2015 un $6.43 \%$ del total de gastos corrientes.

Respecto al destino de los ingresos prediales recaudados en el año 2014, se conoce que cubrieron las partidas presupuestarias del grupo 53 Gastos en Bienes de uso y consumo, de manera específica la subpartida espectáculos culturales y sociales, preservación del patrimonio cultural mediante la realización de las festividades de aniversario del cantón Sucúa. Además, financió la partida presupuestaria del grupo 51 Gastos en el personal, en la subpartida presupuestaria de alimentación y parte de los salarios unificados. En el año 2015 el comportamiento de los ingresos prediales se muestra similar alcanzando el financiamiento del $71.49 \%$ del total de valor destinados al grupo 53 gastos de bienes de uso y consumo.

\section{Referencias Bibliográficas}

Alarcón, M. A. (2009). Hacia un nuevo sistema de imposición directa: el Impuesto a la Renta para el Ecuador un sistema distributivo. Cuadernos de Formación, 8.

Asamblea Nacional. (2008). Constitución de la República del Ecuador. Montecristi: Ediciones digitales.

Asamblea Nacional. (2010). Código Orgánico de Organización Territorial, Autonomía y Descentralización. Quito: Ediciones digitales.

Blacio Aguirre, R. P. (2010). El tributo en el Ecuador. ambitojuridico.com(75). Descargado de http: / /www.ambitojuridico.com.br/ site/index.php?n_link=revista _artigos_leitura\&artigo_id=7639

Clasificador Presupuesdtario de Ingresos y Gastos del Sector Público. (2013). Descargado de http://www.academia.edu/10147312/ Clasificador_Presupuestario -23072013

Congreso Nacional. (2005). Código Tributario del Ecuador. Quito: Ediciones digitales.

Consorcio de Municipios Amazonicos y Galapagos. (2017, marzo). Descargado de http:// www. comaga.org.ec/index.php?option= com_content\&view=article\&id=88: gadm-del-canton-sucua\&catid=24: municipios\&Itemid=101

Dirección de Planificación Estratégica. (2017). Gobierno Autónomo Descentralizado Municipal del Cantón Sucúa. Descargado de www. sucua.gob. ec

González Ortiz, D. (2010). El Tributo. Concepto y características de Tributo.

Impuestos, gobierno y economía:¿aliados o enemigos? (2017, febrero). Descargado de http://investiga.ide.edu.ec/ index.php/impuestos-gobierno-y -economiaialiados-o-enemigos

Paz y Miño Cepeda, J. J. (2015). Historia de los impuestos en Ecuador: visión sobre el régimen impositivo en la historia económica nacional (1a. edición impresa ed.). Quito: Servicio de Rentas Internas del Ecuador SRI. (OCLC: ocn951077899) 
Pinto Bernal, J. J. (2013, Jun). Los orígenes del impuesto directo y progresivo en américa latina. Historia y Sociedad(24), 53-77. Descargado de http: //www.scielo.org.co/ scielo.php?script=sci_abstract $\& p i d=$ s0121-84172013000100002

Ruoti de Doria, N. L. (2006). Lecciones para cátedra de derecho tributario: actualizado de acuerdo a la Ley no. 2.421/04. Asunción, Paraguay: Editora Emprendimientos Nora Ruoti.
Santiere, J., Gómez, J., y Rossignolo, D. (2000). Impacto de los impuestos sobre la distribución del ingreso en Argentina en 1997. Banco Mundial, SPEyR, Ministerio de Economía..

Sauma, J., y Trejos, J. (2014). Gasto público social, impuestos, redistribución del ingreso y pobreza en Costa Rica (Vol. 18). CEQ Working Paper.

Servicio de Rentas Internas del Ecuador. (2017). Servicio de Rentas Internas del Ecuador. Descargado de http://www.sri.gob.ec/web/ guest/impuesto-renta

Recibido: 20 de diciembre de 2017

Aceptado: 13 de marzo de 2018 